\title{
Análise socioambiental: Zona de Educação para Ecodesenvolvimento e Experiência Cooperativa de Mondragón
}

Recebido: 07.12.17

Aprovado: 15.05.18

\author{
Liliane Cristine Schlemer Alcântara* \\ Carlos Alberto Cioce Sampaio** \\ Leire Uriarte Zabala***
}

\author{
* Liliane Cristine \\ Schlemer Alcântara \\ é pós-doutoranda \\ do Programa de Pós- \\ graduação Stricto \\ Sensu em Gestão \\ Urbana da Pontifícia \\ Universidade \\ Católica do Paraná \\ (PUCPR). Doutora \\ em desenvolvimento \\ regional pela \\ Universidade \\ Regional de \\ Blumenau (FURB) \\ com sandwich no \\ Instituto de Estudios \\ Cooperativos (Lanki) \\ da Mondragón \\ Unibertsitatea (MU/ \\ Espanha). Professora \\ do Departamento \\ de Desenvolvimento \\ Rural (DDR) \\ do Centro de \\ Ciências Agrárias \\ (CCA/UFSCar) da \\ Universidade Federal \\ de São Carlos, São \\ Paulo (SP), Brasil. \\ <lilianecsa@yahoo. \\ com.br>.
}

\section{Socio-environmental analysis: ecodevelopment education zone and Mondragon Cooperative experience}

Abstract: This article aims to evaluate the progress and limits of two experiments conducted recently in two different areas on the main aspects involved in the internalization of the environmental issue. They use two case studies: Ecodevelopment Education Zone (ZEE) of the Watershed Rio Sagrado, Morretes (PR); and Mondragon Cooperative Experience (ECM), Basque Country (Spain). The methodology fits as qualitative emphasis applied research; participant research and exploratory, descriptive and evaluative approach with interpretation and data analysis from the qualitative research method of the Collective Subject Discourse (DSC). The results demonstrate that the two experiences work on socio-environmental and socioeconomic management based on the
Carlos Alberto Cioce Sampaio é doutor em engenharia Universidade Federal de Santa Catarina (UFSC) com sandwich em economia social pela École des Hautes Études en Sciences Sociales (Ehess), Paris, França. Pós-Doutor em ciências ambientais pela Washington de produção pela 
State University, USA, em cooperativismo corporativo pela Mondragón Unibertsitatea (MU/ Espanha), e em ecossoecionomia pela Universidad Austral de Chile. Professor e pesquisador do Centro de Pesquisa da Universidade Positivo (CPUP/PR), Curitiba, Paraná (PR), Brasil. <carlos. cioce@gmail.com>.

$* * *$ Leire Uriarte Zabala é mestre em estudos especializados em cooperação para o desenvolvimento pela Univerité Libre de Bruxelles (ULB) e doutora pela Mondragón Unibertsitatea (MU/Espanha). Pesquisadora da Lanki e professora da Faculdade de Humanidades e Ciências da Educação (Huhezi/MU), Instituto de Estudios Cooperativos Lanki/ Huhezi. Mondragon Unibertsitatea,

Espanha.<luriarte@ mondragon.edu> didactic-pedagogical process and the educational praxis: the learning community of the Rio Sagrado with a pedagogical emphasis based on the teaching-learning process; The community of cooperative practice with emphasis on the pedagogical resource of instrumentalization. It was concluded that in their own way, they emerge as alternatives to the hegemonic capitalist logic, working preventively in transforming the local community as protagonists of its development.

Keywords: Eco-development. Cooperativism. Socio-environmental crisis. Sustainable territorial development. Interdisciplinarity.

\section{Introdução}

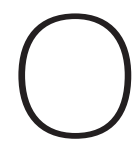
presente trabalho tem como pressuposto o enfoque de educação para o ecodesenvolvimento e educação cooperativa na implementação de estratégias dependerem da capacidade de promover a experimentação com novos sistemas de planejamento e gestão integrada e participativa, bem como condicionada a uma reforma profunda nas práticas educativas convencionais.

Educar sob a perspectiva de um pensamento complexo requer mudanças de modelos mentais dos educadores, partindo da premissa de que os docentes devam indagar, buscar, junto com os educandos, construir relações, histórias e ampliar diferentes contextos. "Trata-se de repensar a escola e de ampliar os espaços educativos que promovam novos saberes e novas práticas sociais" (Tiriba, 2007: 95).

Neste contexto, educar é uma trajetória pedagógica cujo resultado esperado é a emancipação do sujeito (Freire, 1997). Assim, para aprender social e ambientalmente, bem como desenvolver a capacidade de reflexão e mobilização dos atores rumo ao desenvolvimento territorial, faz-se necessário desenvolver competências. Em resumo, além de dispor de saberes - conhecimentos -, um ator deve poder fazer - competências - e também se lançar na ação - competências efetivamente mobilizadas para a ação territorial.

No intuito de subsidiar as adaptações necessárias ao enfoque socioeconômico, pretende-se avaliar os avanços e limites de duas experiências conduzidas recentemente, em dois diferentes territórios, sobre os principais aspectos envolvidos na internalização da questão socioambiental.

Selecionaram-se dois estudos de casos para este estudo: a Zona de Educação para Ecodesenvolvimento (ZEE) da Microbacia do Rio Sagrado, Morretes (PR), no contexto da pedagogia de projetos quanto à temática socioambiental, com um recorte temporal da análise no período de 2006 a 2012; e a Experiência Cooperativa de Mondragón (ECM), País Vasco (Espanha), no âmbito da pedagogia de prática 
social, constituindo-se em arranjo institucional, com recorte temporal compreendendo o período de 2007 a 2015, ambos os espaços de experimentação prática e pedagógica ${ }^{1}$.

O artigo está organizado em seis sessões, incluindo esta Introdução. Na sequência, apresenta-se um breve histórico do desenvolvimento territorial sustentável. Parte-se para o ecodesenvolvimento, a educação para o ecodesenvolvimento, seus aspectos teóricos e históricos. Aborda-se o cooperativismo, a educação cooperativa e sua contribuição para a construção de um modelo alternativo de desenvolvimento. Em seguida, trata-se da metodologia, da caracterização e da análise dos resultados de desenvolvimento socioambiental do Rio Sagrado e do arranjo socioeconômico de Mondragón, em duas seções, e, por fim, são apresentadas as considerações finais.

\section{Desenvolvimento territorial sustentável: rumo a educação socioambiental}

Integrar um pensamento policêntrico e sistêmico à perspectiva ética planetária tornou-se um grande desafio. Mesmo porque os efeitos de uma cultura eurocêntrica e capitalista resultaram em uma crise socioambiental e econômica global sem precedentes. Para Max-Neef, Elizalde e Hopenhayn (2012),

[...] politicamente, a crise é agravada pela ineficiência das instituições políticas representativas contra a ação das elites financeiras do poder, pela crescente internacionalização das decisões políticas e da alta falta de controle que a cidadania tem em burocracias públicas. Contribuem também a configuração de um universo desprovido de uma política com fundamento ético, da automação do controle da vida social, da corrida armamentista e da falta de uma cultura democrática enraizada nas sociedades latino-americanas. Socialmente, a crescente fragmentação das identidades culturais, a falta de integração e comunicação entre os movimentos sociais, o aumento da exclusão social e política e o empobrecimento das massas, têm gerado conflitos incontroláveis dentro das sociedades, impossibilitando as respostas construtivas a tais conflitos. Economicamente, o sistema de dominação sofre mudanças profundas, que afetam substancialmente a globalização da economia, o aumento do capital financeiro com o seu enorme poder concentrador, a crise do Estado de bem-estar social, o crescente envolvimento do complexo militar na vida econômica do país e os múltiplos efeitos de sucessivas ondas de padrões tecnológicos de produção e consumo (Max-Neef, Elizalde \& Hopenhayn, 2012: 24).
1. Esta pesquisa

é resultado da tese de doutorado intitulada Projetos de desenvolvimento: processos de ensinoaprendizagem ou processos de instrumentalização? (Alcântara, 2015), dando origem ao projeto de pesquisa: "Como desenvolver competências por meio da construção de projetos locais?", do Edital Chamada $\mathrm{MCTI} / \mathrm{CNPq} / \mathrm{MEC} /$ Capes n.. 43/2013, do Programa de Pós-Graduação em Gestão Urbana (PPGTU/PUC) em colaboração com o Programa de Pós-Graduação em Desenvolvimento Regional (PPGDR/ Furb).

Ao mesmo tempo, teve como alicerce o projeto de estágio de doutorado no exterior, processo BEX 0381/14-4 na Coordenação de Aperfeiçoamento de Pessoal de Nível Superior (Capes) no Instituto de Estudios Cooperativos de Mondragón Unibertsitatea (Lanki/Huhezi), com o tema "Educação cooperativa para o desenvolvimento territorial sustentável: uma análise de processos pedagógicos de ensino-aprendizagem na construção de projetos de ação territorial", desenvolvido de setembro de 2014 a março de 2015. 
Diante desta crise, o conceito de desenvolvimento passou a ser designado como um processo complexo de mudanças e transformações de ordem econômica, política e, principalmente, humana e social. Desta forma, deixando de significar meramente crescimento econômico para também incluir melhoria do padrão de vida da população (Sandroni, 2004: 83).

Neste contexto, o enfoque do desenvolvimento sustentável teve início com a emergência da problemática socioambiental, nas décadas de 1960 e 1970. Em 1972, Maurice Strong utilizou pela primeira vez o termo ecodesenvolvimento representando uma crítica ao modelo de desenvolvimento hegemônico (Sachs, 1993). Dessa maneira, sem pretender se tornar uma alternativa ideológica para o crescimento, o conceito se ampliou, visando atender às necessidades de superação da miséria, da contaminação ambiental e do caráter perverso do crescimento econômico.

O conceito de desenvolvimento sustentável apresentado no Relatório Brundtland, em 1987, desempenhou papel pedagógico fundamental do ponto de vista socioambiental, além de centrar sua atenção na relação do homem com a natureza, preconizando a utilização racionalizada dos estoques de recursos naturais (Fernandez, 2011). As principais dimensões tratadas deste conceito foram ambiental, social, econômica e político-institucional a abordarem, respectivamente, sustentabilidade, equidade, competitividade e governabilidade.

Segundo o capítulo 35 da Conferência das Nações Unidas sobre Meio Ambiente e Desenvolvimento (Cnumad) uma das bases para a ação exigida do desenvolvimento sustentável foi

[...] assumir perspectivas de longo prazo, integrar os efeitos locais e regionais das mudanças mundiais no processo de desenvolvimento e utilizar os melhores conhecimentos científicos e tradicionais disponíveis (Cnumad, 1992: 2).

Para Gustavo Esteva (2000), a crise socioambiental evidencia a insustentabilidade ecológica e social da racionalidade econômica.

Daí o propósito de internalizar as externalidades socioambientais do sistema econômico ou de submeter o processo econômico às leis ecossistêmicas nas quais se inscrevem (Esteva, 2000: 226).

O desafio é compatibilizar as políticas econômica e ambiental e desencadear um processo no sentido de um desenvolvimento territorial sustentável, relacionado às 
atividades humanas conduzidas em um dado espaço, caracterizando um desenvolvimento endógeno, integrado, comunitário e sustentável.

Nessa perspectiva, se constata a importância da educação relativa à problemática socioambiental, a mais apropriada no sentido complexo-sistêmico-dialético. A intenção básica é dotar indivíduos, grupos sociais e comunidades da capacidade de perceber, compreender e lidar - de forma lúcida, teoricamente bem informada, eticamente refletida e politicamente responsável - com os condicionantes estruturais da crise socioambiental.

Para Carlos Rodrigues Brandão (1995: 26), a educação se constitui em "um meio de produção de poder da sociedade civil e, através dele, um caminho de conquista de participação ativa e consciente" dos rumos da sociedade. Neste sentido, pressupõe-se que a educação para o ecodesenvolvimento e a educação cooperativa oferece um recurso pedagógico importante para o desenvolvimento territorial sustentável. Para Paulo Vieira (2002),

[...] a elucidação da complexidade envolvida na história ecológica da humanidade, a reflexão crítica permanente sobre os fundamentos da cosmovisão ${ }^{2}$ mecanicista-produtivista e dos reflexos nas nossas maneiras de viver, e a defesa (não dogmática) dos ideais regulativos de reverência pela vida e de ecocidadania planetária constituem as dimensões essenciais desse novo paradigma educacional (Vieira, 2002: 7).

De um lado, a concepção de educação para o ecodesenvolvimento integra e transcende os conhecimentos educacionais tradicionais. De outro, a educação cooperativa requer um amplo trabalho não só de educação sociopolítica, mas também ambiental. De acordo com Bruno Jean (2010),

[...] para mostrar as vantagens recíprocas de um enfoque cooperativo capaz de favorecer aquilo que poderia se tornar um grande projeto de sociedade, ou seja, o desenvolvimento territorial solidário (Jean, 2010: 60).

\section{Educação para o ecodesenvolvimento:} gênese do conceito

O conceito de ecodesenvolvimento se apresenta em dois momentos: no primeiro, trata-se de um novo estilo de desenvolvimento aplicável a projetos localizados em áreas rurais e urbanas orientado prioritariamente pela busca da satisfação de necessidades básicas e pela promoção da autoconfiança ou autonomia ou autode-

2. A cosmovisão é um dos prolongamentos da moderna astrofísica. Colocase a questão das origens do universo e o futuro. Petraglia (2008) e Morin consideram esta uma oportunidade de fazer com que uma criança compreenda que tudo de que o universo é constituído formouse desde os primeiros segundos de sua criação; que suas partículas, que seus átomos também são muito antigos, que o carbono de que ele é feito provem de sóis anteriores... Nós somos totalmente filhos deste universo, mesmo sendo singulares. 
terminação (self-reliance) das populações envolvidas no processo; no segundo, o conceito designa também um enfoque participativo de planejamento e gestão de estratégias plurais de intervenção, adaptadas a contextos socioambientais específicos (Vieira, 2002). O conceito de ecodesenvolvimento foi assim enunciado:

Um processo criativo de transformação do meio, com a ajuda de técnicas ecologicamente prudentes, concebidas em função das potencialidades deste meio, impedindo o desperdício inconsiderado dos recursos, e cuidando para que estes sejam empregados na satisfação das necessidades reais de todos os membros da sociedade, dada a diversidade dos meios naturais e dos contextos culturais. Promover o ecodesenvolvimento é, no essencial, ajudar as populações envolvidas a se organizar, a se educar, para que elas repensem seus problemas, identifiquem suas necessidades e os recursos potenciais para receber e realizar um futuro digno de ser vivido, conforme os postulados de justiça social e prudência ecológica (Sachs, 2007: 58).

Fikret Berkes et alii (2001) e Paulo Vieira (1999) apontam para a importância da valorização do conhecimento dos membros da comunidade no processo de cogestão adaptativa de recursos comuns; afirmam que esse reconhecimento da cultura local se dá a partir de uma pedagogia social de corte sistêmico, o qual possibilita que uma comunidade perceba a dinâmica coevolutiva que se mantém com o meio ambiente biofísico e a importância dessa inter-relação para a recriação da vida comunitária. Esse enfoque incentiva o empoderamento das comunidades locais e a participação das instituiç̧̃es na gestão dos recursos naturais, visando novas estratégias de desenvolvimento local, considerando a problemática socioambiental.

Neste sentido, Paulo Freire percebe a educação como comunicação, diálogo, encontro de pessoas que procuram a razão de ser dos acontecimentos, pois, para ele,

a educação é diálogo ou não é educação (Freire, 1971: 109). [...] O educador não é aquele que somente ensina, mas aquele que, durante a ação educativa, é também educado pelo diálogo com o educando (Freire, 2009: 68).

Para o autor, o ser humano é um projeto inacabado:

[...] a educação que se impõe aos que verdadeiramente se comprometem com a libertação não pode fundar-se numa compreensão dos homens como seres "vazios" a quem o mundo encha de conteúdos; não pode basear-se numa consciência especializada, mecanicistamente compartimentada, mas nos homens como "corpos conscientes" e na consciência como consciência intencio- 
nada ao mundo. Não pode ser a do depósito de conteúdos, mas a da problematização dos homens em suas relações com o mundo (Freire, 2009: 38).

A educação para o ecodesenvolvimento se configura como alternativa de educação voltada para o desenvolvimento local. Trata-se, na verdade, de uma revisão nos paradigmas educacionais vigentes, nas estratégias e situações concretas de ensino-aprendizagem a partir do pensamento complexo-sistêmico (Nascimento \& Pereira, 2003).

Neste contexto, é necessário desenvolver atitudes de respeito com a natureza, ressaltando os sentidos de autonomia, resultando em um estilo solidário, como sugere a autopoiese, traduzido como o "centro da dinâmica constitutiva dos seres vivos" (Maturana \& Varela, 1980: 87). Neste sentido, uma das propostas pedagógicas centrada na educação como um processo de aquisição e prática da autonomia por meio das reações construídas pelos indivíduos são as Zonas de Educação para o Ecodesenvolvimento (ZEEs).

[...] Espaços em que se privilegia o conhecimento, a compreensão, a proposição e o agir sobre o território de maneira que se conservem modos de vida tradicionais e se preserve a biodiversidade (Sampaio et alii, 2016: 149).

Deste modo, as Zonas de Educação para o Ecodesenvolvimento privilegiam ações de caráter interdisciplinar, em um esforço que percorre desde o diálogo entre diversas disciplinas pertinentes às demandas levantadas pelos territórios até a hibridização da sabedoria popular com conhecimentos científicos úteis ao território onde a ZEE se instala (Raynaut, 2011).

A importância de um processo educativo-participativo recai no fato de dialogar com moradores, comunidade escolar, funcionários, pais, professores, alunos, no sentido de desenvolver um processo de participação com o objetivo de identificar projetos locais por meio da comunidade de aprendizagem. A comunidade de aprendizagem é uma estratégia pedagógica que tem por objetivo estabelecer novas relações com o meio ambiente, desenvolver um projeto concreto em torno de um aspecto de um problema socioambiental. Esta estratégia pode ser pensada como processo de educação a partir do cotidiano, inspirado no esforço de educação para o ecodesenvolvimento, na identificação de problemas e proposição de soluções, estimulando competências e autonomia (Sauvé, 2001: 32).

Entre as potencialidades da educação para o ecodesenvolvimento estão: 
i. estímulo a uma nova visão de mundo que permite compreender como os sistemas estão imbricados entre si;

ii. estímulo a uma nova visão de educação em que o desenvolvimento humano seja percebido contextualmente e se realize integralmente;

iii. possibilidade de socialização entre o conhecimento científico e o conhecimento tradicional sem hierarquização e através do diálogo de saberes; e,

iv. abertura para a unidiversidade humana a partir do convívio coletivo, numa esfera de comunidade de aprendizagem (Morin, 2003).

Desenvolve-se, assim, o sentimento de filiação com o ambiente de vida e o sentimento de responsabilidade, resultando num enriquecimento mútuo, onde é estimulada a criatividade, contribuindo para melhorar as relações com o meio ambiente para propiciar o desenvolvimento do pensamento crítico e a questão dos valores, que levam a descobrir e a diagnosticar as situações-problema.

Assim, importa introduzir critérios ecológicos e um quadro interdisciplinar alinhado com um enfoque sistêmico e global das realidades para identificar projetos locais, que promovam um modo de conhecimento capaz de apreender os objetos em seu contexto, sua complexidade, seu conjunto (Morin, 1999). O cerne das estratégias de ecodesenvolvimento é estar, em última instância, baseado em experimentações locais que traduzem objetivos globais. Ressalta-se que para esse enfoque, a educação é uma premissa, ou seja, não poderá existir ecodesenvolvimento sem educação para o ecodesenvolvimento (Sachs, 1980; 2007; Vieira, 1999).

Presume-se que a educação para o ecodesenvolvimento deva tratar a conservação da biodiversidade; a autorrealização individual e comunitária, em consonância com a educação para a cidadania, por meio de processos educativo-participativos, promoveriam o desenvolvimento em todas as suas dimensões e fundamentalmente como qualidade de vida (Sachs, 1980). Desse modo, diretrizes pedagógicas são dadas, sobretudo pelos preceitos da educação popular de Paulo Freire, que tem na pedagogia a possibilidade de libertação dos indivíduos, a partir de um processo que não se encerra em salas de aula e menos ainda com excesso de informações depositadas sobre aprendizes. 


\section{Educação cooperativa: gênese do conceito}

O cooperativismo é considerado como um dos principais instrumentos para a promoção de desenvolvimento econômico e social ao gerar e distribuir renda, e promover o capital social nas comunidades que o praticam (Bialoskorski Neto, 2002). Segundo Nora Amodeo (2013) uma gestão social cooperativista constitui-se em,

[...] um campo complexo e multidimensional de conhecimentos, métodos e práticas, que têm como objetivo o desenvolvimento do relacionamento dos cooperados com a cooperativa, do sentimento de pertencimento, da identidade, da fidelidade e da confiança entre os associados e sua cooperativa, mediante a participação, a capacitação, a comunicação e o fluxo de informações entre todos os membros da organização, elementos todos que contribuirão para um democrático e economicamente eficiente exercício do poder na cooperativa (Amodeo, 2013: 2).

Neste contexto situa-se a educação cooperativa, vista como componente pedagógico da gestão social, sendo considerada essencial para o modelo de gestão cooperativista. Afinal, uma boa administração cooperativa se atinge pelo caminho da educação e da formação. Para José Carlos Libâneo (1998),

o pedagógico refere-se a finalidades da ação educativa, implicando objetivos sociopolíticos a partir dos quais se estabelecem formas organizativas e metodológicas da ação educativa (Libâneo, 1998: 22).

A educação cooperativa serve como estratégia que impulsiona o desenvolvimento. Ao elevar a si mesmo como promotor da proposta cooperativista no intuito de defender e promover o desenvolvimento como estratégia de ensino, deve-se pensar em um modelo que permita manter uma organização para os seres humanos.

A educação cooperativa no desenvolvimento de competências atende às propostas de desenvolvimento territorial, materializadas em programas e projetos que passam a ganhar significado no momento de sua implementação. Ao mesmo tempo, volta-se

ao desenvolvimento da pessoa humana, plenamente consciente do seu papel na cooperativa e consequentemente na sociedade, uma pessoa solidária e altruísta, comprometida por laços de reconhecimento com sua comunidade (Schneider, Hendges, \& Silva, 2010: 17). 
O que se procura por meio da educação cooperativa é uma educação integral à classe trabalhadora e que propicie a emancipação humana; ao invés de uma formação instrumental e de interesses para atender às demandas do mercado de trabalho. José Valadares (2005) define educação cooperativa como

[...] um processo e um método para formular e executar políticas de educação e comunicação cujas características se referem a aspectos essenciais à prática da cooperação: a gestão democrática. Compreende o processo propriamente dito de preparação e adoção de planos e estratégias por decisões das bases cooperativistas e dos dirigentes e sua execução por parte do órgão responsável pela administração do serviço educacional e pelo esquema de organização comunitária adotada pela cooperativa (Valadares, 2005: 33).

Deste modo, educar para o trabalho significa que o aluno deva trabalhar intelectualmente pelo manejo prático das coisas, construindo uma realidade interna subjetiva, que se traduz, por sua vez, em determinado resultado que, no caso, é o aprendizado, foco de interesse na atividade laboral educativa, o que caracteriza a comunidade de prática. Para Jean Lave e Etienne Wenger (1991) uma comunidade de prática,

[...] é uma condição intrínseca para a existência de conhecimento, não apenas porque ela providencia um suporte interpretativo necessário para dar sentido à sua herança. A participação na prática cultural na qual qualquer conhecimento ocorre é um princípio epistemológico de aprendizagem. A estrutura social de sua prática, suas relações de poder, e suas condições para legitimação definem possibilidades para a aprendizagem (Lave \& Wenger, 1991: 98).

José Schneider (2003) afirma que, para determinar se um sistema é educativo ou não, é preciso verificar se ele proporciona, sob que aspecto e em que medida, o desenvolvimento das capacidades e das personalidades dos indivíduos atendidos por esse mesmo sistema. Então, a cooperativa em si é um espaço ideal para a aprendizagem e o desenvolvimento das habilidades, os quais devem levar à geração de propostas inovadoras em termos de gestão, cooperação e desenvolvimento da comunidade.

A educação deve fortalecer a ideia e a realidade de que a cooperativa é um ator social capaz de gerar resultados positivos e eficientes para o bem comum e o desenvolvimento territorial. A perspectiva de educação mais se aproxima da cooperativa em sua dimensão de "associação de pessoas", enquanto a capacitação, em suas diversas acepções, mais se aproxima da cooperativa em sua dimensão "empresa", como explicam José Schneider, Margor Hendges e Antônio César Silva (2010): 
A educação abarca a formação sobre a visão do mundo, da vida e da economia própria do cooperativismo, compreende a formação de valores, dos princípios essenciais, das normas e sua aplicação concreta dentro das circunstâncias econômicas, sociais, políticas, culturais de todo o país e de cada região. A formação e a capacitação atuam de forma técnica nos métodos e nos procedimentos relacionados com a gestão eficiente da empresa cooperativa, como instrumento do cooperativismo (Schnneider, Hendges \& Silva, 2010: 31).

A educação e a cooperativa estão vinculadas, como o trabalho ao homem, que se autorrealiza individual e coletivamente. "A educação é o fundamento da base e do espírito cooperativo; a própria cooperativa pode ser considerada como uma escola" (Azurmendi, 1992: 244). A educação é entendida como prática cooperativa prévia à promoção cooperativa propriamente dita.

Neste sentido, a educação cooperativa pode ser entendida como educação social, que deve levar os indivíduos e os grupos a repensarem e reformarem os seus próprios conhecimentos e suas experiências confrontando o conteúdo recebido com o que já detém. O objetivo desta educação é formar transformadores do mundo, preparando homens responsáveis e constantes, aptos a construírem um mundo mais justo, novo e solidário, cultivando a inteligência e o espírito associativo.

Ao mesmo tempo, leva-se em conta que a educação cooperativa é considerada um dos principais instrumentos para o desenvolvimento econômico e social, com o objetivo de gerar renda e promover o capital social nas comunidades.

O processo de formação engloba tanto o desenvolvimento pessoal como o desempenho profissional das pessoas envolvidas. Do mesmo modo, os cooperados devem reconhecer na educação e na formação cooperativista uma oportunidade para desenvolver competências, conhecimentos, ferramentas e habilidades que permitem melhores resultados para a sua base social.

Desta forma, um modelo de ensino-aprendizagem deveria ter a consciência de que sua função é prestar serviços e o resultado final deve ser o bem-estar dos indivíduos e da melhoria contínua da qualidade de vida. Para isso, a educação cooperativa deve gerar processos de formação consistente, a fim de desenvolver estratégias de ação que visem gerar retornos econômicos e retornos sociais em equilíbrio contínuo. 0 desafio é como pensar a educação em longo prazo em sua dimensão pedagógica para a contribuição na construção e desenvolvimento de competências, conhecimentos, habilidades, saberes e fazeres para as práticas socioambientais na perspectiva interdisciplinar. 


\section{Metodologia}

O estudo foi desenvolvido na Zona de Educação para o Ecodesenvolvimento do Rio Sagrado, Morretes (PR), Brasil, com um recorte temporal de análise do período de 2006 a 2012; e a Experiência Cooperativa de Mondragón (ECM), Espanha (País Vasco), com recorte temporal compreendendo o período de 2007 a 2015 (Alcântara, 2015).

Apesar do desafio do estudo realizado em diferentes territórios, percebeu-se potencialidades importantes entre ambos que validaram este estudo: apresentam aproximações envolvidas na questão socioambiental; resultam em alternativas de desenvolvimento regional; e são espaços de experimentação prática e pedagógica.

A metodologia utilizada para este estudo teve uma abordagem interdisciplinar e o processo de aprendizagem uma concepção epistemológica, sistêmica-práxis-humanista (Bertalanffy, 1975). Com base em sua natureza e abordagem a pesquisa foi aplicada qualitativa; do ponto de vista dos procedimentos técnicos tratou-se de estudo de caso, utilizando de observação participante e na análise de dados da pesquisa exploratório-descritiva e avaliativa com interpretação e análise de dados a partir do método de pesquisa qualitativa do discurso do sujeito coletivo (DSC) , como apresentado na Tabela 1.

As informações coletadas na pesquisa partiram de dois momentos: dados primários por meio de entrevistas semiestruturadas e observação participante e dados secundários em fontes e bibliografias sobre o tema. As entrevistas na Zona de Educação

TABELA 1

PROCEDIMENTOS DE PESQUISA

\begin{tabular}{|c|l|l|l|}
\hline \multirow{2}{*}{ Etapas } & \multicolumn{1}{|c|}{ Procedimentos de pesquisa } & Técnicas de pesquisa & Quanto ao delineamento \\
\hline Primeira etapa & Referencial teórico & $\begin{array}{l}\text { Aplicada qualitativa } \\
\text { Exploratória }\end{array}$ & $\begin{array}{c}\text { Pesquisa bibliográfica } \\
\text { Análise documental }\end{array}$ \\
\hline Segunda etapa & $\begin{array}{l}\text { Caracterizar os aspectos } \\
\text { pedagógicos, (socioambientais e } \\
\text { socioeconômicos) dos projetos } \\
\text { de desenvolvimento: ambiental e } \\
\text { democrático }\end{array}$ & $\begin{array}{l}\text { Aplicada qualitativa } \\
\text { Estudo de caso } \\
\text { Exploratório-descritiva }\end{array}$ & $\begin{array}{l}\text { Pesquisa bibliográfica } \\
\text { Análise documental } \\
\text { Entrevistas não diretivas } \\
\text { Observação participante }\end{array}$ \\
\hline Terceira etapa & $\begin{array}{l}\text { Caracterizar e analisar as } \\
\text { competências que levam ao } \\
\text { processo de formação-educação } \\
\text { interdisciplinar/transdisciplinar } \\
\text { voltada ao desenvolvimento }\end{array}$ & $\begin{array}{l}\text { Estudo de caso } \\
\text { Exploratório-descritiva }\end{array}$ & $\begin{array}{l}\text { Entrevistas não diretivas } \\
\text { Observação participante } \\
\text { Análise das entrevistas por } \\
\text { meio do discurso do sujeito } \\
\text { coletivo (DSC) }\end{array}$ \\
\hline Quarta etapa & $\begin{array}{l}\text { Considerações e conclusões a } \\
\text { partir dos resultados alcançados }\end{array}$ & Avaliativa & Considerações finais \\
\hline
\end{tabular}

Fonte: elaborado pelos autores. 
para o Ecodesenvolvimento levaram em conta o seguinte público-alvo: gestores do projeto, alunos, professores, a comunidade e os pais de alunos. Na Experiência Cooperativa de Mondragón, a pesquisa teve como público-alvo: professores, alunos, pesquisadores, presidentes de cooperativa, ex-cooperados e a comunidade não cooperativista. Foram entrevistados 40 representantes dos grupos de atores-chave, levando-se em conta o conceito sistêmico de ecodesenvolvimento e do cooperativismo conforme as categorias sociais envolvidas.

\section{Contextualização das experiências}

Desenvolvimento socioambiental:

ecodesenvolvimento

A Zona de Educação para o Ecodesenvolvimento (ZEE) foi criada em 2006 e está localizada na Microbacia Hidrográfica de Rio Sagrado, no litoral sul do Paraná (Figura 1), cujo território pertence à Área de Preservação Ambiental (APA) de Guaratuba, faz parte da Reserva da Biosfera de Floresta Atlântica (ReBIO), sendo esta uma das áreas da floresta Atlântica contínuas mais preservadas do Brasil (Mansur, 2013). Esta característica do território foi capaz de criar uma identidade local valorizando sua cultura, seus atrativos naturais, históricos e econômicos. Esta estratégia pode ser identificada na questão dos recursos naturais, na valorização do território e na preservação da mata e dos rios pela comunidade.

FIGURA 1

MAPA DE LOCALIZAÇÃO DA MICROBACIA HIDROGRÁFICA DO RIO SAGRADO, MORRETES (PR) E MAPA DE COMUNIDADES DA MICROBACIA

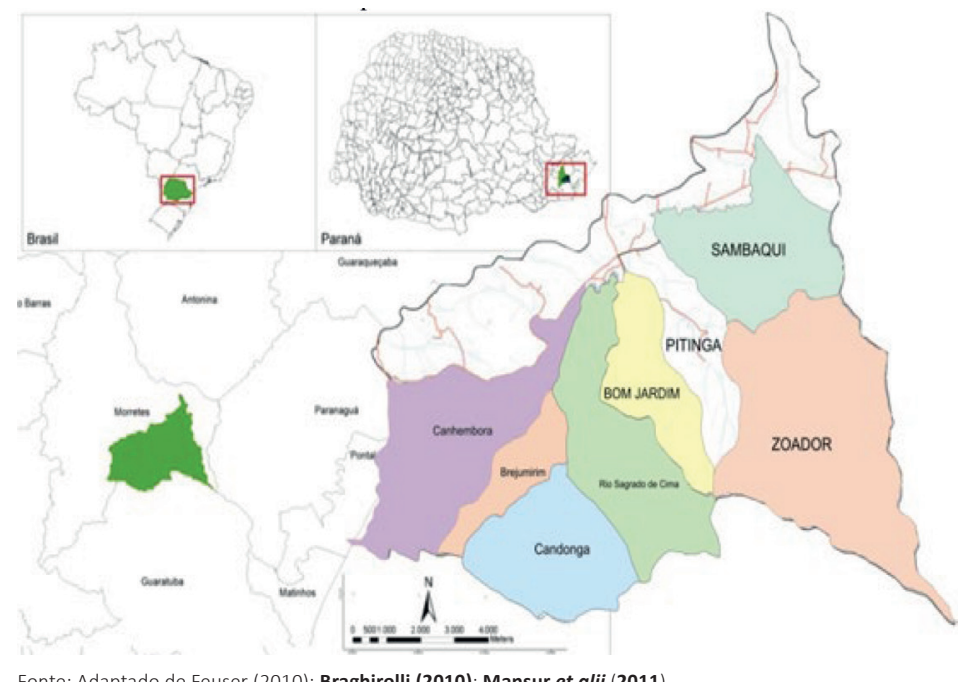

Fonte: Adaptado de Feuser (2010); Braghirolli (2010); Mansur et alii (2011) 
A comunidade do Rio Sagrado é composta por pequenas propriedades rurais com agricultura de subsistência (Feuser \& Braghirolli, 2010). Entretanto, a ausência de perspectivas econômicas contribuiu para o fortalecimento do êxodo rural, sobretudo entre os jovens, em busca de trabalho nas grandes cidades. Segundo os agricultores, esta realidade mudou com a perspectiva da chegada do turismo comunitário, fortalecida com a possibilidade das vivências comunitárias, feiras de trocas, advinda do projeto intervivência universitária, intitulado Programa de Honra de Estudos e Práticas de Ecossocioeconomia.

O Programa de Honra obteve financiamento do Edital 23/2008 pelo Conselho Nacional de Desenvolvimento Científico e Tecnológico (CNPq)/Ministério da Ciência e Tecnologia (MCT) conjuntamente com o Fundo Setorial do Agronegócio (CT-Agronegócio)/Ministério do Desenvolvimento Agrário (MDA), edital este encampado pela Universidade Regional de Blumenau (Furb) e Universidade Federal do Paraná (UFPR). O Programa de Honra teve uma duração de dois anos e os planos de ensino tinham uma orientação interdisciplinar, visto que os conteúdos partiam de problemas identificados no território pelos moradores de Rio Sagrado. O objetivo foi articular ensino, pesquisa e extensão, de forma interdisciplinar rumo à transdisciplinaridade, integrando membros comunitários, acadêmicos da iniciação científica, estudantes do Programa de Pós-Graduação.

O projeto, eminentemente interdisciplinar, deu origem a subprojetos que se complementaram entre si, voltados a atender a demanda da comunidade:

\footnotetext{
A base epistemológica claramente definida, necessária à prática interdisciplinar foi a conservação de modos de vida tradicionais e a preservação da biodiversidade dos territórios que compõem a Microbacia do Rio Sagrado (Grimm et alii, 2015: 133).
}

Neste sentido, o turismo comunitário surge como um projeto de desenvolvimento, a partir do fortalecimento da identidade comunitária, por meio de geração de trabalho e renda associada às tecnologias apropriadas do território. A demanda de projetos desenvolvidos no período de 2006 a 2012 atenderam as dimensões de sustentabilidade do ecodesenvolvimento preconizadas por Sachs (1993): social, econômica, ecológica, espacial e cultural, buscando soluções específicas dos problemas particulares daquela comunidade, levando em conta os dados ecológicos e culturais. Houve também, por meio dos projetos, a valorização dos recursos específicos da região, valorização do homem local e da cultura; redução dos impactos ambientais e principalmente educação preparatória rumo à educação para o ecodesenvolvimento. 
Percebe-se que apesar da exuberância ambiental da comunidade da ZEE do Rio Sagrado, representada pelas paisagens: abundância dos recursos hídricos, da Mata Atlântica e ocorrência de um relevo que alterna áreas dos vales dos rios, morros e montanhas, existem alguns pontos de fragilidade ambiental na comunidade (Alcântara et alii, 2015).

Conclui-se que o desenvolvimento chegou ao Rio Sagrado, não em termos econômicos, mas fundamentalmente como um avanço da tomada de consciência e solidariedade que contrasta com a destruição ambiental e desigualdade social. Não se pode negar que este enfoque demanda novos projetos, bem como a continuidade de formação e educação para o ecodesenvolvimento, que respondam às mudanças profundas que ocorrem simultaneamente no campo econômico, político e social.

Encontrou-se na comunidade pesquisada uma realidade na qual a maioria dos membros comunitários dispõe de terras, sistemas de produção alimentar e recursos que Ihes permitem cobrir suas necessidades básicas sem ter que recorrer ao mercado. Assim, pode-se distinguir entre o conceito de uma vida simples e pouco agressiva com a natureza: a agricultura de subsistência a que muitos estão sujeitos, restringe a sua participação nos mercados locais, em contrapartida, garante-lhes uma vida simples, pouco agressiva com a natureza, ar puro e silêncio nas estimativas que procuram "medir" a qualidade de vida.

\section{Desenvolvimento de arranjo institucional: cooperativismo}

O Cooperativismo de Mondragón nasceu no século XX, nos anos do pós-guerra civil, mais precisamente em 1956, e seus fundamentos seguiam os princípios de seu fundador Arizmendiarrieta, que desencadeou uma ação coletiva transformadora, cultural e identitária no momento em que o mundo de pertencimento e sentido havia sido destroçado (Azurmendi, 1992).

Em dezembro de 1991, aprovou-se, durante o Terceiro Congresso Cooperativo, um novo projeto organizacional e o Grupo Cooperativo Mondragón passou a se chamar Mondragón Corporación Cooperativa (MCC). Este novo projeto organizacional buscou a máxima eficiência empresarial setorial, reagrupamento das cooperativas com relações de produto-mercado mais homogêneas e unidade de direção estratégica. Este novo esquema organizacional contempla hoje a existência de quatro grupos: industrial (com doze divisões), financeiro, educação e distribuição ${ }^{2}$ (Figura 2).

2. Dados disponíveis em: $<$ www. mondragoncooperativa.com>. 
FIGURA 2

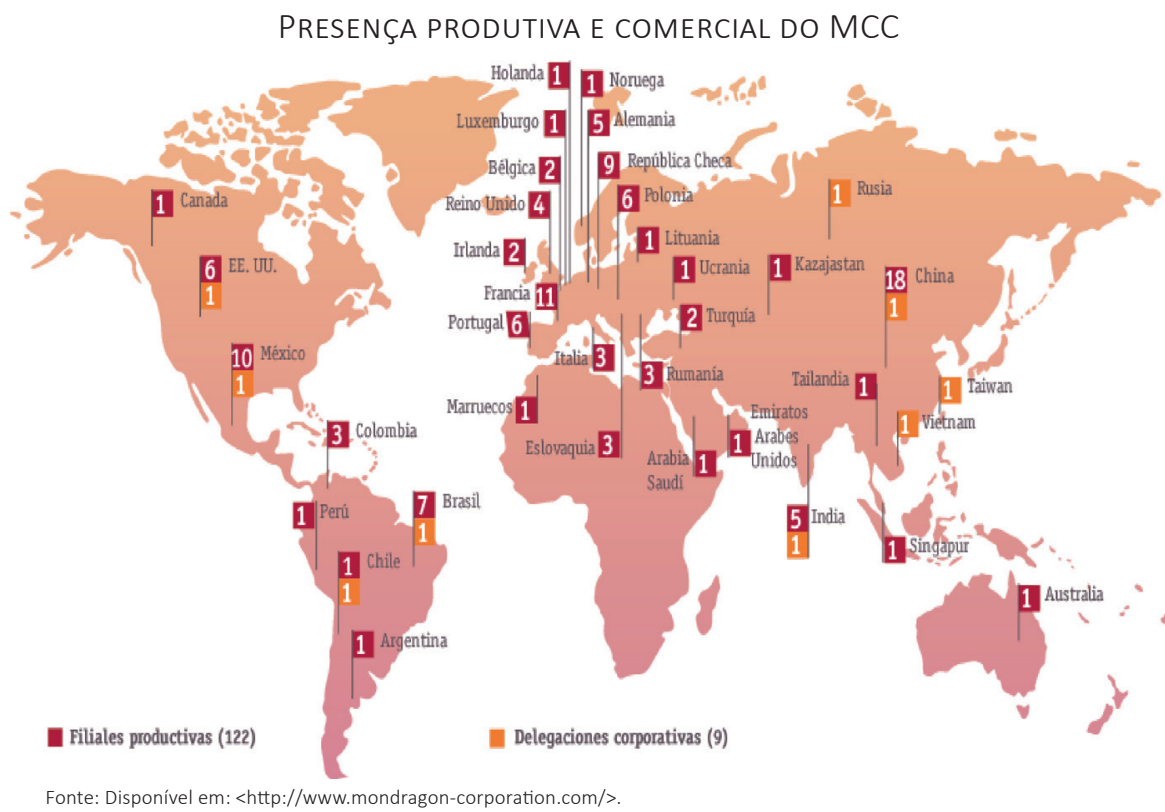

O conflito entre capital e trabalho constituiu a contradição fundamental da sociedade industrial do século passado. A esse conflito se intentou dar uma resposta pela ação cooperativa inspirada no pensamento autogestionário. A origem do cooperativismo é que imprime o caráter do seu modelo participativo (Alcântara, Sampaio \& Uriarte, 2016).

O cooperativismo de Mondragón fundamenta-se em dez princípios,

que constituem a sua base de funcionamento e, ao mesmo tempo, se materializam numa prática, ou numa ascese, que é síntese de uma ética, a ética católica de Arizmendiarrieta (Sampaio et alii, 2012: 154).

Estes princípios são: livre adesão, organização democrática, soberania do trabalho, instrumentalização e subordinação do capital, gestão participativa, solidariedade distributiva, cooperação, transformação social, universalidade e educação. Para Arizmendiarrieta (1984), a educação devia ser o início de tudo. Embora fosse uma premissa, nem sempre foi considerada na prática cooperativista.

Portanto, quando se considera a educação como o primeiro e o principal princípio, trata-se de uma educação que se desloque da racionalidade antropocêntrica, como a que fundamentou priori- 
tariamente a prática do cooperativismo de Mondragón, para uma racionalidade socioambiental na qual haja a compreensão de que os sistemas são integrados, premissa a partir da qual os processos decisórios devem ser norteados (Sampaio et alii, 2012: 163).

Em 2005, realizou-se uma reflexão sobre o sentido da Experiência Cooperativa de Mondragón e pensou-se em novos processos de inovação e desenvolvimento de uma estratégia de educação cooperativa. Esta estratégia foi instrumentalizada depois do Proceso de reflexión sobre la evolución del sentido de la experiencia cooperativa de Mondragón.

A estratégia de recuperação e revitalização cooperativa veio com os esforços simultâneos do Departamento de Gestão Social do Grupo Cooperativo da Mondragón Unibertsitatea (MU), por meio do Instituto de Estudios Cooperativos (Lanki). Para seu desenvolvimento, formou-se um grupo de trabalho misto, composto por membros da Comissão Permanente do Grupo Mondragón e investigadores de Lanki, que se encarregaram do seguimento das sessões, da sistematização da informação, da análise dos resultados e da elaboração do diagnóstico final (Udaondo, Azkarrga \& Iñurrategi, 2012: 2).

Para Arizmendiarrieta (1984), as principais razões do debate sobre estes temas se entende como: participação democrática a caracterizar essencialmente a dimensão interna das cooperativas; compromisso e responsabilidade social; meta de transformação social; e educação como instrumento e fundamento do movimento cooperativista. Neste contexto, buscou-se um processo educativo que desse a direção, o rumo e o sentido para a mudança e transformação social. Deste modo, o Cooperativismo de Mondragón, em parceria com o Instituto de Estudios Cooperativos de Mondragón Unibertsitatea (Lanki/Huhezi), Bagara Herrigintzan, S. Coop. e a Fundação Mundukide trabalham em conjunto com projetos de transformação social.

Um formato de educação cooperativa desenvolvido por Lanki e o cooperativismo pelo Centro de Desarrollo Directivo y Cooperativo de Mondragón (Otalora) que prevê uma educação cooperativa em três formatos: cursos de oito horas, cursos de formação de dois a três dias para órgãos sociais e diretivos e cursos de Pós-graduação com duração de 250 horas. Na parceria com "Bagara Herrigintzan, S. Coop" procura-se desenvolver projetos de educação e competências voltadas a transformação social. Seus princípios se voltam na busca de novos modos de produção e consumo consciente, valoração do homem e da comunidade, agricultura baseada em métodos biologicamente mais saudáveis, novas formas de administração e de propriedade comum, dentre outros. 
As ações realizadas até o presente momento acontecem de duas formas: em primeiro nível na valorização das entidades educativas, língua euskera e cultura Vasca; em segundo nível se valorizam e se promovem diversas obras sociais e de assistência, meio ambiente, atividades culturais e esportivas e apoio a países em desenvolvimento com a Fundação Mundukide.

Para os atores sociais, o cooperativismo de Mondragón concebe-se como promotor de um desenvolvimento comunitário com chave autogestionária e também um polo ativo de criação de emprego e riqueza, onde a educação tem uma função social, um dever que vai mais além da escola e um âmbito que deve ser dividido com outros agentes sociais. A educação cooperativa vem se empreendendo por meio de propostas que ofereçam significado para as cooperativas. O modelo de educação cooperativo contém quatro elementos e tem como objetivo impulsionar uma nova etapa da formação para a educação cooperativa, além de sistematizar, atualizar e fazer uma permanente formação cooperativa.

1. Fase de Planejamento:

1. definição de objetivos de médio e curto prazo;

2. valoração dos recursos necessários (financeiros, pessoas etc.); e

3. tempo das ações.

2. Fase de desenvolvimento:

1. Programa A: órgãos sociais;

2. Programa B: quadros executivos, novas incorporações e restante de sócios; e

3. Curso avançado: responsáveis de formação cooperativa e membros de órgãos-líderes sociais.

3. Fase de evolução:

1. evolução do processo de implantação; e

2. evolução da qualidade das ações educativas realizadas.

4. Fase de reflexão-investigação e ajustes:

1. reflexão e investigação para desenvolver novos materiais formativos e novas metodologias; e

2. reflexão sobre a evolução do próprio modelo. 
Entretanto, na visão dos entrevistados falta uma definição clara do objetivo social e empresarial; ao mesmo tempo há dificuldade de planejar o projeto social cooperativo e o espírito participativo mais consciente. Para Ortega e Uriarte (2015)

[...] o desenvolvimento de uma cultura e uma identidade de acordo com as bases e demandas do paradigma cooperativo parece um dos desafios imediatos que enfrentam as cooperativas (Ortega \& Uriarte, 2015: 28).

Neste contexto, o cooperativismo carece de uma formação que estimule as capacidades e competências dos indivíduos para a resiliência, capacitando-os para que possam se antecipar à crise social, econômica e ecológica, sem perder sua identidade, o que pressupõe flexibilidade adaptativa. Bem como, conciliar a capacidade de imaginar novas formas de relação com a natureza e a comunidade, partindo do pressuposto de que os seres humanos, em qualquer cultura, têm que produzir uma relação harmônica com o ambiente como condição para um desenvolvimento de sua própria natureza.

\section{Análise de resultados}

A análise se deu à luz das informações coletadas na pesquisa por meio de entrevistas semiestruturadas e observação participante com os atores-chave das duas experiências e análise de dados a partir do método de pesquisa qualitativa do discurso do sujeito coletivo (DSC).

\section{Zona de educação para o ecodesenvolvimento}

O diagnóstico da situação atual de desenvolvimento na comunidade analisada demonstra que se necessita de maior integração entre os atores (redes de transporte insuficientes, mercados locais sem comunicação entre si, pouca participação social). Frente a este quadro percebe-se a necessidade de continuidade de um desenvolvimento integrado para o estudo da realidade e para a continuidade de projetos de ação e educação para o ecodesenvolvimento.

Olha, é bem desunido, é bem desunido, você acha assim, chama o povo é complicado, assim, pra participa... No caso, reunião por causa da água, essas coisa, assim, é difícil. Isso que o cara que trabalha aqui na água, ele vai de casa em casa, assim, então ele é bem comunicativo nesse ponto. E mesmo assim, o povo não se interessa de participa, né? (DSC 1).

O enfoque do conhecimento tácito dos especialistas e os saberes da comunidade presentes na cultura local a partir da observação e da prática de vida partem da 
própria experiência. Neste sentido, as equipes interdisciplinares deveriam buscar interpretações multicausais para os problemas ou situações que se pretendem tratar, levando em conta a interdependência dos sistemas como um conceito chave para a integração e a complexidade dos mesmos.

No projeto de desenvolvimento realizado no território, destacaram-se processos de ensino-aprendizagem, por meio da pedagogia de projetos, utilizando-se da instrumentalização como apoio metodológico. Apesar de ter atendido seus propósitos, como o turismo comunitário por meio das vivências, feiras de troca e o fortalecimento das associações (Associação Comunitária Candonga e Amorisa), não teve continuidade por parte da comunidade e algumas atividades se encerraram. Ou seja, alguns princípios foram assimilados, entretanto, a precariedade e a fragilidade do capital social resultaram na desmobilização da comunidade.

Quando eu comecei aqui, tinha gente que perguntava o que era a associação, eles não sabiam o que era a associação, e moravam aqui... Essa associação já existia há dez anos, eles não sabiam o que que era, nem o que era a cozinha comunitária, pessoas que moram do ladinho aqui, dois quilômetros, não sabiam por que ela existia. Sabia que tinha um prédio aqui, mas nem pra que existia (DSC 2).

A associação necessita ser fortalecida e vista por parte dos associados como um "porto seguro" que contribui com o desenvolvimento regional para fortalecer a imagem da ZEE como uma região de preservação ambiental de um futuro onde prevalecerá uma forma de desenvolvimento que privilegie dois aspectos: a qualidade de vida de seus habitantes e a melhoria de todos aqueles que a visitam.

Frente a grave crise ecológica e social que a humanidade enfrenta, importa construir um modelo de desenvolvimento menos antropocêntrico que não dilapide o ecossistema e planeje estilos de vida fundamentados em um tipo de consumo mais responsável.

Nós tomamo água do rio aí. Não temo outra água, só do rio. Então continua, que nem nós cuidamo, tipo, a gente cuida bastante pras outras pessoas que vêm de fora não destruir, continua sempre, é lixo, a gente vive brigando, assim, falando, brigando não, falando né? (DSC 3).

A Zona de Educação para o Ecodesenvolvimento de Rio Sagrado, como espaço de estudo, pesquisa e práticas com perspectiva interdisciplinar rumo à transdisciplinaridade possui potencialidades como: conservação de modos de vida tradicionais e biodiversidade. 
Daí o que a gente sentiu assim: é que muitas coisas assim veio, mas daí parou, não deu continuidade, sabe, daí a gente vê assim muita coisa veio, teve tanta participação, tanta coisa e paro! Não teve continuidade, não foi dado continuidade nas coisa pra prossegui né?" (DSC 4).

Entretanto, como se percebe o protagonismo dos sujeitos e o agir local sobre o território demonstrou ser insuficiente para a continuidade dos projetos.

\section{Experiência cooperativa de Mondragón}

A ordem social das sociedades industriais modernas cresceu sob a luz de uma nova ideia: produtividade. Nesta realidade, natureza e sociedade humana sempre viveram sob a égide da questão temporal, onde natureza e recursos se renovam em períodos lentos, não acompanhando o ritmo acelerado dos sistemas produtivos. Não foi diferente no cooperativismo de Mondragón.

Na sociedade há cada vez mais o individualismo [...] valores mais coletivos tem cada vez menos força. Valores mais individualistas são mais fortes, estes são cada vez mais fortes. E nas cooperativas também, estes valores ficam a desejar. Preocupam-se mais com o negócio, a rentabilidade... O projeto social perde força, essa leitura nas Cooperativas de Mondragón não é mais a mesma (DSC 1).

O cooperativismo carece de uma formação que estimule as capacidades e competências dos indivíduos para a resiliência, capacitando-os para que possam se antecipar à crise social, econômica e ecológica, sem perder sua identidade, o que pressupõe flexibilidade adaptativa. Bem como, conciliar a capacidade de imaginar novas formas de relação com a natureza e a comunidade, partindo do pressuposto de que os seres humanos, em qualquer cultura, têm que ter uma relação harmônica com o ambiente como condição para um desenvolvimento da sua própria natureza.

Um dos grandes problemas encontrados nas cooperativas foi a própria conscientização dos trabalhadores em relação à importância de sua participação social. Ao considerar que os valores da sociedade capitalista atual - onde cada vez mais o Ter é mais importante que o Ser - reflete-se nos grupos na dificuldade do ser cooperativo, na questão da solidariedade.

Foi feito um diagnóstico em todo grupo Mondragón e as conclusões foram diversas. Porém, sobretudo eram três: a educação, a participação e a transformação social... uma parte é que não estava sendo feito uma transmissão cooperativa entre as diferentes cooperativas, pelo menos estrutural, e que agora as novas tives- 
sem os mesmos valores que tinham os que fundaram o cooperativismo. Desde aí, se viu que havia uma carência (DSC 2).

Neste sentido, há um esforço participativo do cooperativismo de Mondragón por meio da educação, em aproximar a gestão cooperativa dos cooperados, o que pressupõe um desenvolvimento humano rumo à sustentabilidade ecológica, social e econômica.

Temos que iniciar esta reflexão. Então se conclui que a formação da educação nas cooperativas, há muita formação técnica. Aqui nestes anos, muita formação técnica, porém o cooperativismo falta! Formação humana falta! Cooperativo humano. É uma reflexão (DSC 3).

O objetivo está em criar um espaço de transparência dos processos como garantia de eficiência e eficácia no cumprimento dos objetivos comuns rumo ao bem-estar no contexto da vida cooperativista. Ao mesmo tempo, é uma oportunidade para a aprendizagem coletiva e um reforço aos valores e atitudes democráticas. Percebeu-se que a dimensão educativa da experiência não se desenvolveu totalmente, ainda que a dimensão técnico-empresarial tenha tido um crescimento exponencial.

\footnotetext{
Há que se trabalhar tudo. Este é um enfoque que queremos plantar aqui. Aqui entra a sustentabilidade ecológica, que é importante. Aqui a sustentabilidade ecológica teria que ser importante, está relacionado. Teremos algo bonito que será traçado aqui. Não há como fazer educação sem isto. Se a comunidade está mal, se não cuidar isto, não vão conseguir... Entendemos que faltam no momento estratégias de educação. Vivemos numa sociedade individualista, consumista. Há que se dar importância também a esta dimensão, é importante (DSC 4).
}

Ao mesmo tempo, a educação das novas gerações do entorno cooperativo, incluindo aqueles educados dentro da experiência, esbarra na falta de capacidade de dar razão ao fazer cooperativo com mais espírito crítico. Outro aspecto identificado foi o caráter mais racional-instrumental da educação que, entretanto, procura avançar por meio da valoração substantiva e da interdisciplinaridade nos processos de ensino-aprendizagem, enfatizando relações interpessoais, cultura e liderança nos cursos de formação.

Entretanto, infere-se que o eixo educativo é transversal a toda comunidade e percebe-se que há um esforço coletivo na prática de transformação social e desenvolvimento comunitário, canalizando a educação cooperativa como vetor procurando revitalizar a própria identidade cooperativa. 


\section{Considerações finais}

Diante do objetivo de avaliar os avanços e limites de duas experiências conduzidas recentemente, em dois diferentes territórios, sobre os principais aspectos envolvidos na internalização da questão socioambiental, concluiu-se que ambas a seu modo apresentam formas alternativas de educação em desenvolvimento regional, trabalhando preventivamente na transformação da comunidade local como protagonista de seu desenvolvimento.

Percebeu-se que as duas experiências, no âmbito do desenvolvimento territorial sustentável, apresentam aproximações importantes no que tange ao aspecto de arranjo institucional, caracterizando-se como tal. Com base no levantamento tanto teórico como Ortega e Uriarte (2015 empírico realizado, pode-se concluir que as duas dinâmicas socioprodutivas abordadas apresentam similitudes e algumas diferenças. A primeira busca soluções no âmbito ambiental e social; enquanto a segunda, nas suas variáveis, no âmbito econômico e social. De qualquer forma, as propostas não se excluem, mas se complementam.

Igualmente, ambas possuem uma compreensão sistêmica da realidade, requerendo, entretanto, maior articulação da práxis. Neste sentido, o desafio teórico e operacional é fazer com que as propostas deem continuidade aos processos de formação e educação, seja ela formal ou informal, tendo como prioridade o desenvolvimento de uma visão sistêmica, inter e transdisciplinar, demonstrando inter-relação dos processos socioeconômicos e socioambientais, frente aos desafios colocados pelo mundo globalizado.

Apesar dos percalços que precedem o desenvolvimento de competências, vislumbra-se a educação para o ecodesenvolvimento e a cooperativa, fatores de expressão e realização dos princípios ambientais e de transformação social rumo ao desenvolvimento territorial sustentável.

Inicialmente, pode-se inferir que os princípios do ecodesenvolvimento foram assimilados pela comunidade do Rio Sagrado, não necessitando de um processo formal de educação para ter compreensão que a promoção do desenvolvimento requer participação, comprometimento, cooperação e solidariedade. Ou seja, as necessidades humanas e o bem-estar são conceitos vivenciados no dia a dia, na convivência.

Entretanto, necessita-se de mecanismos para criar um contexto social e familiar que assegure a permanência das pessoas da comunidade no seu território, favorecendo o estabelecimento de um modelo produtivo que, além de ecologicamente susten- 
tável, seja economicamente viável e culturalmente aceitável. Neste caso específico, necessita-se fortalecer o item de eficiência econômica. Ao mesmo tempo, carecem de maior empoderamento, emancipação, autonomia autogestionária e lideranças capazes de dar continuidade aos processos que levam ao desenvolvimento territorial sustentável.

Uma segunda inferência, é que a experiência de cooperativismo de Mondragón, ainda que seja uma referência na perspectiva da socioeconomia, não contém elementos substantivos para ser caso emblemático em ecossocioeconomia. Apesar dos esforços visíveis da corporação cooperativa por meio da educação transformadora, não apresenta avanços enquanto concepção sustentável de vanguarda.

Dentro desta perspectiva, percebe-se que a comunidade de aprendizagem do Rio Sagrado passou a dispor de um conjunto de conhecimentos teóricos e práticos socioambientais que lhes permitiu analisar e relativizar os efeitos negativos antrópicos ao meio ambiente, utilizando-se do processo de ensino-aprendizagem como recurso pedagógico e da instrumentalização como apoio metodológico. De outro lado, a comunidade de prática do cooperativismo procurou fortalecer o aspecto relacionado à transformação social, primando por projetos de revitalização social da comunidade e do entorno, utilizando-se como recurso pedagógico a instrumentalização, caminhando gradativamente rumo ao processo de ensino-aprendizagem.

Neste sentido, a prática interdisciplinar e/ou multidisciplinar foi essencial para a análise de problemas complexos, como os sociais e ambientais, porque permitiu a comunicação de saberes e a cooperação articulada entre os diversos atores, levando em conta as diferentes perspectivas para a interpretação e/ou soluções das questões teóricas e práticas.

Ao mesmo tempo, necessita-se pensar soluções em nível macro e micro, preservando os princípios e valores, pilares das diferentes propostas, incluindo a gestão democrática e autogestionária, na busca de um modelo alternativo de desenvolvimento, justo, solidário e democrático, que privilegie acima de tudo, uma sustentabilidade ecológica, social e econômica.

As lições que auferimos nesta pesquisa sobre o enfoque do ecodesenvolvimento e do cooperativismo não são somente sobre gestão socioambiental e/ou socioeconômica, mas sobre as possibilidades de se construir uma nova sociedade que compreenda a verdadeira noção de sustentabilidade. 


\section{Referências}

ALCÂNTARA, Liliane Cristine Schlemer. Projetos de desenvolvimento: processos de ensino-aprendizagem ou processos de instrumentalização? Tese (Doutorado em Desenvolvimento Regional) - Programa de Pós-graduação em Desenvolvimento Regional, Universidade Regional de Blumenau, Blumenau, 2015.

ALCÂNTARA, Liliane Cristine Schlemer; PELLIN, Valdinho.; SAMPAIO, Carlos Alberto Cioce; SOUZA, Cristiane Mansur de Moraes. Zona de Educação para o Ecodesenvolvimento: aproximação da Universidade com a Comunidade. Desenvolvimento e Meio Ambiente, v. 33, 2015. Disponível em: <http://ojs.c3sl.ufpr.br/ojs/index.php/ made/article/view/35943>. Acesso em: 24 Maio 2018.

ALCÂNTARA, Liliane Cristine Schlemer; SAMPAIO, Carlos Alberto Cioce; URIARTE, Leire Zabala. Desenvolvimento de competências: uma concepção da pedagogia de projetos e da pedagogia de prática social. In: SOUZA, Cristiane Mansur de Moraes; SAMPAIO, Carlos Alberto Cioce; ALVES, Alan Ripoll; ALCÂNTARA, Liliane Cristine Schlemer (Orgs.). Novos talentos: processos de educação para o ecodesenvolvimento. Blumenau: Nova Letra Editora, 2016.

AMODEO, Nora Beatriz Presno. Educação e comunicação cooperativista: reflexões sobre educação e comunicação cooperativista. Viçosa, MG: [s.n.], 2013.

ARIZMENDIARRIETA, José María. La empresa para el hombre. Mondragón: Caja Laboral Popular, 1984.

AZURMENDI, Joxe. El hombre cooperativo: pensamento de Arizmendiarrieta. Mondragón: Caja Laboral popular; Lan Kide Aurrezkia, 1992.

BERTALANFFY, Ludwig von. Teoria geral dos sistemas. 2. ed. Petrópolis (RJ): Vozes, 1975.

BERKES, Fikret; MAHON, Robin; MCCONNEY, Patrick; POLLNAC, Richard; POMEROY, Robert. Managing small-scale fisheries fikret berkes: alternative directions and methods. Ottawa (CA): International Development Research Centre, 2001.

BIALOSKORSKI NETO, Sigismundo. Estratégias e cooperativas agropecuárias: um ensaio analítico. In: BRAGA, M. J.; REIS, B. S. (Orgs.). Agronegócio cooperativo: reestruturação e estratégias, p. 77-97. Viçosa: Universidade Federal de Viçosa: 2002.

BRANDÃO, Carlos Rodrigues. Em campo aberto: escritos sobre a educação e a cultura popular. São Paulo: Cortez, 1995. 
CONFERÊNCIA DAS NAÇÕES UNIDAS SOBRE MEIO AMBIENTE E DESENVOLVIMENTO (CNUMAD). Agenda 21. 1992. Disponível em: <http://www.mma.gov.br/responsabilidade-socioambiental/agenda-21/agenda-21-global>. Acesso em: 25 Maio 2018.

ESTEVA, Gustavo. Desenvolvimento. In: SACHS, Wolfang. Dicionário do desenvolvimento: guia para o conhecimento como poder. Petrópolis(RJ): Vozes, 2000.

FERNANDEZ, Brena Paula Magno. Ecodesenvolvimento, desenvolvimento sustentável e economia ecológica: em que sentido representam alternativas ao paradigma de desenvolvimento tradicional? Desenvolvimento e Meio Ambiente, n. 23, p. 109120, Jan./Jun. 2011.

FEUSER, Shimene; BRAGHIROLLI, G. Análise dos fatores físico-naturais da comunidade Rio Sagrado de Cima, Microbacia Hidrográfica do Rio Sagrado. Mostra Integrada de Ensino, Pesquisa e Extensão - Mipe. Blumenau: Furb, 2010.

FREIRE, Paulo. Pedagogia do oprimido. 48. reimpressão. São Paulo: Paz e Terra, 2009.

—. Pedagogia da autonomia. São Paulo: Paz e Terra, 1997.

—. Educação como prática da liberdade. Rio de Janeiro: Paz e Terra, 1971.

GRIMM, Isabel Jurema; DIAS, Adriana; SAMPAIO, Carlos Alberto Cioce; FERNANDES, Valdir. Interdisciplinaridade e práticas no ecodesenvolvimento: análise da microbacia do Rio Sagrado, Morretes, PR. Ambiente e Sociedade [on-line], v. 18, n. 1, p. 115134, 2015. Disponível em: <http://www.scielo.br/pdf/asoc/v18n1/pt_1414-753X-asoc-18-01-00115.pdf>. Acesso em: 01 Abr. 2018.

JEAN, Bruno. Do desenvolvimento regional ao desenvolvimento territorial sustentável: rumo a um desenvolvimento territorial solidário para um bom desenvolvimento dos territórios rurais. In: VIEIRA, P. F. et alii. Desenvolvimento territorial sustentável no Brasil: subsídios para uma política de fomento. Florianópolis: Aped/Secco, 2010.

LAVE, Jean; WENGER, Etienne. Situated learning: legitimate peripheral participation. Cambridge (UK); New York: Cambridge University Press, 1991.

LEFÈVRE Fernando; LEFÈVRE Ana Maria Cavalcanti. Depoimentos e discursos: uma proposta de análise em pesquisa social. Brasília; LiberLivro, 2005.

LIBÂNEO, José Carlos. Pedagogia e pedagogos, para quê? São Paulo: Cortez, 1998.

MANSUR, Cristiane de Moraes Silva; SAMPAIO, Carlos Alberto Cioce; ZUÑIGA, Christian Henriquez; PASCO, Adriana Dias; AUMOND, José Juarez. Diagnóstico e construção de indicadores socioambientais participativos: experiências de um programa de extensão. Revista Brasileira de Ciências Ambientais, n. 30, Dez. 2013. 
MATURANA, Humberto R.; VARELA, Francisco J. Autopoiesis and cognition: the organization of the living. Boston: Reidel, 1980.

MAX-NEEF, Manfred; ELIZALDE, Antonio; HOPENHAYN, Martin. Desenvolvimento à escala humana: concepção, aplicação e reflexões posteriores. Blumenau: Edifurb, 2012.

MORATO, Adelvânio Francisco; COSTA, Alisson. Avaliação e estratégia na formação educacional cooperativista. In: MACÊDO, K. B.; XIMENES, J. A. A. (Orgs.). Cooperativismo na era da globalização. Goiânia: UCG/Terra, 2001.

MORIN, Edgar. A cabeça bem feita: repensar a reforma, reformar o pensamento. 8. ed. Rio de Janeiro: Bertrand Brasil, 2003.

Os sete saberes necessários para a educação do futuro. Paris: Unesco, 1999.

NASCIMENTO, Carolina Cavalcanti; PEREIRA, Maiara Leonel. Educação para o ecodesenvolvimento: narrativa preliminar de um processo em construção. 2003. Disponível em: <www.nmd.ufsc.br>. Acesso em: 15 Mar. 2018.

ORTEGA, I. S.; URIARTE L. Z. Retos y dilemas del Cooperativismo de Mondragón tras la crisis de Fagor Electrodomésticos. Cuadernos de Lanki, n. 10, 2015.

PETRAGLIA, Izabel. Edgar Morin: a educação e a complexidade do ser e do saber, 10. ed. Petrópolis: Vozes, 2008.

RAYNAUT, Claude. Interdisciplinaridade: mundo contemporâneo, complexidade e desafios à produção e à aplicação de conhecimentos. In: PHILIPPI JR, A.; SILVA NETO, A. J. Interdisciplinaridade em ciência, tecnologia \& inovação. Barueri (SP): Manole, 2011.

SACHS, Ignacy. Ambiente e estilos de desenvolvimento. In: SACHS, I.; VIEIRA, P. F. (Orgs.). Rumo à ecossocioeconomia: teoria e prática do desenvolvimento, p. 54-76. São Paulo: Cortez, 2007.

- Estratégias de transição para o século XXI: desenvolvimento e meio ambiente. São Paulo: Estúdio Nobel, 1993.

— Stratégies de l'écodéveloppement. "Collection Développement et Civilisations". Paris: Les Éditions Ouvrières, 1980.

SAMPAIO, Carlos Alberto Cioce; ARAUJO, Jussara R.; HENRÍQUEZ Zuniga, Christian ; PASCO, Adriana Dias. Educación para el ecodesarrollo: micro-cuenca del Río Sagrado. In: SOUZA, Cristiane Mansur de; SAMPAIO, Carlos Alberto Cioce; ALVES, Alan Ripoll; ALCANTARA, Liliane Cristine Schlemer (Orgs.). Novos talentos: processos de educação para o ecodesenvolvimento, v. 1, p. 147-164. Blumenau: Nova Letra, 2016. 
SAMPAIO, Carlos Alberto Cioce; FERNANDES, Valdir; ETXAGIBEL, Joseba Azkarraga; ALTUNA, Larraitz Gabilondo. Revisitando a experiência de cooperativismo de Mondragón a partir da perspectiva da ecossocioeconomia. Desenvolvimento e Meio Ambiente, n. 25, p. 153-165, Jan./Jun. 2012.

SANDRONI, P. Novíssimo dicionário de economia. São Paulo: Nova Cultura, 2004.

SAUVÉ, Lucie. L'éducation relative à l'environnement. Québec: HMH, 2001.

SCHNEIDER, José Odelso. (Org.). Educação cooperativa e suas práticas. São Leopoldo (RS): Editora Unisinos, 2003.

SCHNEIDER, José Odelso; HENDGES, Margot; SILVA, Antônio César Machado da. Educação e capacitação cooperativa: os desafios no seu desempenho. São Leopoldo (RS): Editora Unisinos, 2010.

TIRIBA, Lia. Educação popular e pedagogia(s) da produção associada. Cadernos Cedes, v. 27, n. 71, Jan./Abr. 2007.

UDAONDO, Ainara; AZKARRAGA, Joseba; IÑURRATEGI, Iñigo. Proceso de reflexión cooperativo en las cooperativas de Mondragón. Comunicación en XIV Jornadas Nacionales de Investigadores en Economía Social. El año internacional de las Cooperativas: desafíos y propuestas de la economía social en un mundo en transformación, Ciriec, Donostia, 2012.

VALADARES, José Horta. Profissionalização da gestão cooperativista: modismo ou necessidade? Revista Universo, Ano 3, n. 16, 2005.

VIEIRA, Paulo Freire. Repensando a educação para o ecodesenvolvimento. In: Tecnologia e cidadania. Anais do VIII Encontro Nacional de Ensino Agrícola. Camboriú (SC), Out. 2002.

- Repensando a educação para o ecodesenvolvimento. In: VIEIRA, P. F.; RIBEIRO, M. A. (Orgs.). Ecologia humana, ética e educação. A mensagem de Pierre Dansereau. Porto Alegre; Florianópolis: Pallotti; Aped, 1999. 